\title{
IMPACTO DEL MARCO INSTITUCIONAL EN EL DESARROLLO DE LAS ORGANIZACIONES EMPRESARIALES EN EL PERÚ*
}

\author{
Antonio Díaz Andrade \\ ASISTENTE ACADÉMICO DE ESAN \\ Área de Operaciones, Métodos Cuantitativos y Sistemas
}

\section{Resumen}

Investigación exploratoria que busca identificar los aspectos de la institucionalidad del país que han influido e influyen, positiva o negativamente, en el desarrollo de las organizaciones empresariales en el Perú. El modelo diseñado muestra las relaciones de interdependencia entre cultura, educación, Estado y globalización. El artículo presenta también un marco conceptual para propiciar el debate serio sobre la importancia de este tema y esboza lineamientos sobre el papel que les compete a las organizaciones empresariales en el desarrollo económico y social del país.

onsiderando el importante papel que las empresas juegan en el desarrollo de un país y el aparente irregular desempeño de las empresas en el Perú, en comparación con sus pares situadas en otras latitudes, esta investigación trata de hallar una probable explicación de por qué aquellas no han alcanzado en nuestro país el éxito que la sociedad y ellas mismas esperaban.

Ponencia presentada al sétimo congreso internacional de la Western Academy of Management. Lima, 6-10 de julio de 2002. El autor quiere expresar su reconocimiento a Gabriela Hiromoto, Alejandro Rozas, Francisco Sagasti y Luis Felipe Silva-Santisteban, con quienes
Al respecto, puede suponerse que algunos factores clave pueden haber estado ausentes o no haber operado como debieran para promover el desarrollo de las organizaciones empresariales en el Perú. ¿Son acaso los empresarios peruanos menos capaces que sus similares de otros países? ¿El Estado peruano no ha sabido fomentar el desarrollo sustentado en la creatividad e iniciativa de sus ciudada-

realizó la tesis del mismo título en que se basa el presente artículo y con la cual todos los mencionados optaron el grado de Magíster en Administración. Sin embargo, la actualización y las modificaciones a la versión original son únicamente responsabilidad del autor. 
nos? ¿Han sido los constantes cambios de políticas económicas y sociales beneficiosos para las empresas? ¿La educación ha estado orientada a motivar el espíritu emprendedor de los peruanos? ¿La diversidad cultural ha favorecido el desarrollo de las empresas?

Ante estas interrogantes podrían surgir múltiples respuestas; sin embargo, con la finalidad de encauzar la investigación y realizar un análisis extenso, se ha buscado la respuesta en el marco institucional en el que se desenvuelven las empresas peruanas. De esta manera, se pretende echar luces sobre un tema controvertido y quizá poco tratado desde la perspectiva empresarial e identificar los aspectos de la institucionalidad del país que han influido e influyen, positiva o negativamente, en el desarrollo de las empresas en el Perú. Adicionalmente, se busca construir un marco conceptual que permita propiciar el debate serio sobre la importancia de la institucionalidad para el desarrollo económico y social del país, y luego esbozar lineamientos sobre el papel que les compete a las organizaciones empresariales en este proceso.

\section{Marco conceptual}

Desde una perspectiva social y antropológica, las instituciones son convenciones construidas por los grupos humanos que comparten sus pensamientos y armonizan sus preferencias. Dado que las instituciones reducen la entropía, solamente dentro de ellas las comunidades pueden tomar grandes decisiones (Douglas, 1996).

Según el enfoque filosófico desarrollado por Wittgenstein (citado por Bloor, 1997), las instituciones sociales se tradu- cen en reglas; en consecuencia, seguir una regla involucra una referencia a la actuación de otros miembros de la comunidad e implica participar en una institución y, por tanto, adoptar o conformar una costumbre o convención. La institucionalidad no se crea al reglamentarla; es la sociedad la que crea la institucionalidad al interiorizar una norma de comportamiento; así, las reglas existen en y a través de la práctica de citarlas y evocarlas, de alentar a otros a seguirlas. El finitismo constituye las barreras de contención que previenen a los individuos de divergir de las reglas; un sujeto siente el deber de seguir las reglas porque existe una actitud colectiva respecto de ellas. La cultura, como ente externo, es la razón de que se perciban las reglas como existentes y propias de una realidad independiente que obliga al individuo a seguirlas; de este modo, los individuos están impelidos por las reglas siempre que colectivamente se fuercen unos a otros a cumplirlas (Bloor, 1997).

Según la teoría de la nueva economía institucional, cuyo principal objeto de estudio son las instituciones sociales para analizar, con un enfoque interdisciplinario, los aspectos políticos y económicos del desarrollo social y sus interdependencias, las instituciones constituyen el marco en cuyo interior se desarrolla la interacción humana, son una guía para las relaciones humanas e incluyen todo tipo de limitación que los individuos crean con ese fin. Esta teoría considera que las instituciones juegan un papel clave en el proceso de transformación de los factores de producción en bienes y servicios (North, 1993).

En esta misma corriente de pensamiento, el concepto de institución incluye a 
las estructuras y reglas que moldean la conducta humana y «contribuyen a formar y estabilizar las expectativas del individuo respecto de la conducta de otros individuos» (Pritzl, 1996: 223). Las instituciones existen para reducir la incertidumbre que surge de la complejidad del proceder humano y sus interacciones; es decir, gracias a las instituciones los individuos saben cómo deben proceder en determinadas circunstancias (North, 1993). En consecuencia, la conducta de los agentes económicos no depende solamente de sus propios gustos y preferencias, como lo sugiere la teoría económica pura, también está determinada por el marco institucional, que impone un límite al conjunto de elecciones posibles.

El respeto a las normas se origina en muchos casos en la costumbre, pues las personas tienden a respetar determinada regla por el hábito de hacerlo. Cuando Ortega y Gasset decía «Yo soy yo y mis circunstancias», no hacía sino describir a la persona inmersa en su situación; por lo tanto, estaba negando la idea de que los pensamientos y creencias puedan abstraerse de sus antecedentes y el contexto social. Así, las instituciones no son sólo ideas independientes, también son creencias al interior de una cultura.

Es usual llamar institución al conjunto de leyes que forman el ordenamiento jurídico de un país; sin embargo, son las instituciones las que sostienen a las leyes. Por un lado, la institución preexiste a la ley; esto significa que es una norma de conducta de la sociedad y constituye una institución informal. Si esta institución promueve el desarrollo de la sociedad, el Estado tenderá a reforzarla por medio de la ley, convirtiéndola en una institución formal. Por otro lado, hay leyes que pretenden convertirse en institución, para lo cual es necesario el consentimiento social. Sobre este proceso de aceptación e interiorización social se levanta el orden jurídico de cada país, que será sólido en la medida en que se sustente tanto en el castigo por el incumplimiento de la ley como en la presión de la sociedad (Bloor, 1997).

Las organizaciones constituyen la expresión estructural de la acción racional, que se ve afectada por las características sociales de sus miembros y las diversas presiones impuestas por su medio ambiente (Selznick, 1948). Las entidades que realizan sus actividades dentro de las convenciones establecidas, es decir, las instituciones, no son otra cosa que las organizaciones. Éstas son creadas por los individuos con la finalidad de maximizar la riqueza o lograr otros objetivos definidos por las oportunidades que brinda el marco institucional. Las organizaciones, que incluyen cuerpos políticos, económicos, sociales y órganos educativos, proporcionan también, al igual que las instituciones, una estructura para la interacción humana (North, 1993).

Debido a que son sistemas sociales con metas y procedimientos que tienden a seguir un estatus establecido, las organizaciones se convierten en instituciones con el tiempo (Selznick, 1948). «Las instituciones [...] determinan las oportunidades que hay en una sociedad. Las organizaciones son creadas para aprovechar esas oportunidades $\mathrm{y}$, conforme evolucionan los organismos, alteran las instituciones» (North, 1993: 18-19). Las instituciones y los organismos equivalen a las reglas de juego y a los jugadores, respectivamente. 
En una sociedad compleja, las acciones deshonestas tienden a incrementarse, por lo que resulta indispensable una tercera parte coercitiva que haga posible cumplir los contratos. Para ello, es necesaria la creación de procedimientos de control, los que constituyen precisamente el marco institucional, y éste, a su vez, comprende las limitaciones formales e informales (North, 1993).

Las instituciones formales están constituidas por reglas de orden político, judicial y económico, entre otras, creadas con un fin específico. Sin embargo, las normas formales constituyen sólo una pequeña parte de las instituciones que limitan las elecciones de los individuos, pues de hecho abundan las limitaciones informales. Estas últimas son reglas derivadas de la tradición, religión y convenciones y corresponden a códigos de conducta transmitidos socialmente que han evolucionado a través del tiempo y son parte de la cultura. La cultura es muy importante en el análisis de la conducta y las decisiones que toma el individuo, porque define un marco conceptual en la interpretación de toda la información que aquél recibe (Bloor, 1997, y North, 1993).

Las reglas, en su mayoría, derivan del autointerés y son creadas para beneficiar a ciertos grupos (North, 1993). Si el marco institucional no es el adecuado para el logro de los objetivos de determinados grupos, a éstos les interesará promover el cambio. Este cambio será posible solamente cuando alterar el marco formal implique beneficios para los grupos que tienen suficiente capacidad de negociación. Si esto es así, las organizaciones alterarán en forma lenta y continua o en forma violenta y discontinua las instituciones formales (North, 1993).
Si se tiene en cuenta que uno de los aspectos que rigen la conducta humana es el beneficio personal, en algunos casos las reglas de conducta establecidas podrían ser dejadas de lado y originar situaciones en las que se trasgreda los límites legales definidos. A estas situaciones la nueva economía institucional las denomina oportunismo, el que se puede manifestar a través de «la mentira, el robo y el engaño, pero no se limita a ellas. Más a menudo, el oportunismo comprende algunas formas sutiles de engaño» (Williamson, 1989: 226) .

En el marco de la nueva economía institucional, el rentismo y los grupos de interés constituyen elementos centrales -además de los derechos de propiedad y los costos de transacción- y serán de especial utilidad para el desarrollo de la presente investigación.

El rentismo se describe como una operación por la cual se trata de ejercer influencia en el proceso político-burocrático para la modificación de los derechos de propiedad. El objetivo del rentismo no es aumentar las actividades productivas, sino, más bien, redistribuir lo producido hasta el momento; luego, las actividades rentistas demuestran ser socialmente improductivas (Pritzl, 1996).

Un grupo de interés es aquel que trata de hacer valer los propios intereses en el proceso político, sobre todo con vista a la obtención de ventajas distributivas. Mientras más homogéneos sean los intereses compartidos por un grupo y cuanto mejor organizado sea éste, más probable será que se alcance esas ventajas distributivas (Pritzl, 1996). 
Una perspectiva sistémica permitirá el análisis de las variables del entorno institucional que de alguna forma determinan la dinámica empresarial. Surge así, del enfoque filosófico de Wittgenstein (citado por Bloor, 1997) y del enfoque social y antropológico de Douglas (1996), la necesidad de considerar a la cultura como uno de los factores básicos para entender el desempeño de las empresas en una sociedad. La cultura es el conjunto de significados, valores y creencias consolidadas y compartidas que caracterizan a una nacionalidad, un grupo étnico, entre otros, y orienta sus comportamientos (Faure y Rubin, 1993). La cultura conlleva el mejoramiento de las facultades físicas, intelectuales y morales del hombre y de la sociedad; de esta manera, cada generación debe comprender los productos culturales de las precedentes y asimilar lo que en ellos conserve validez y haga posible el progreso (García, 1964).

Del mismo modo, Bloor (1997) resalta la importancia del aprendizaje para seguir las reglas establecidas para la convivencia social. Por lo tanto, la educación se convierte en uno de los elementos más poderosos con los cuales forjar, reforzar o modificar la cultura de un grupo humano, ya que el proceso educativo «consiste en la asimilación de la cultura del grupo en que se vive; [...] la educación es una función social y [...] es la sociedad la encargada de realizarla» (Benton, 1964: 102). En el fomento del espíritu creador, que permite el progreso del individuo y de las instituciones, radica la importancia de la educación, al moldear una cultura de progreso y de desarrollo.

Del pensamiento de Pritzl (1996), quien considera que el Estado no debe ser solamente un árbitro para la reduc- ción de los costos de transacción, sino también la entidad responsable de crear instituciones que eliminen las trabas del desarrollo social sostenido, se desprende la necesidad de incluir al Estado en el análisis. El Estado no es sino la sociedad organizada, es sólo un ente abstracto fruto de lo que Rousseau denominó el contrato social; en consecuencia, el poder del Estado emana del pueblo; es el pueblo mismo el que al ejercer el poder debe hacerlo cumpliendo con las limitaciones establecidas por las leyes. El Estado, a través de sus diferentes poderes, es responsable de emitir normas y velar por el cumplimiento de las mismas, de tal manera que la sociedad se desenvuelva en un ambiente armónico y de seguridad y se promueva el bienestar general. Uno de los deberes primordiales del Estado es «promover el bienestar general que se fundamenta en la justicia y en el desarrollo integral y equilibrado de la Nación» (Constitución Política del Perú, 1993).

Por otro lado, el sector externo ejerce una influencia poderosa sobre la colectividad, más aún en la época actual, cuando los avances en la tecnología de las telecomunicaciones y la cada vez más marcada interdependencia entre los estados del mundo definen lo que se ha dado en llamar el fenómeno de la globalización. La globalización representa al sector externo en cuanto y en tanto es un factor no originado dentro de las fronteras del país, pero que influye en la institucionalidad a través de la continua interacción con las entidades de éste.

Adicionalmente, debe notarse que la evolución de las organizaciones altera las instituciones (Pritzl, 1996), toda vez que, según la teoría de la nueva economía institucional de North (1993), aquellas son 


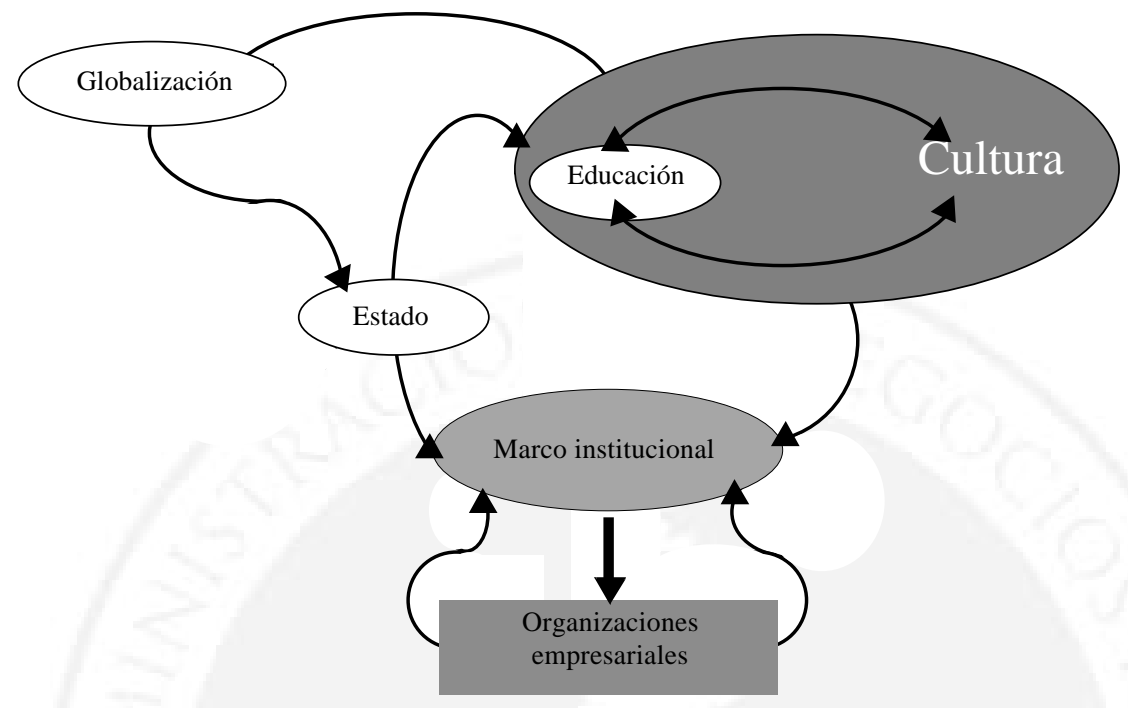

Figura 1. Modelo de investigación

creadas para aprovechar las oportunidades que las instituciones determinan. Así, las organizaciones empresariales también pueden modificar el marco institucional.

La figura 1 representa el modelo diseñado para esta investigación y muestra las relaciones de interdependencia entre las diferentes variables que modelan las instituciones, las que, a su vez, afectan el desarrollo de las organizaciones empresariales en el Perú.

\section{Metodología}

Por la naturaleza del tema, que involucra conceptos de orden económico, político, social y cultural sobre los cuales no necesariamente existe uniformidad de criterios, el esfuerzo de investigación estuvo orientado a buscar pistas que permitan formular interrogantes con las cuales lograr una mejor comprensión del mismo. La investigación tuvo carácter exploratorio, pues debido a la falta de datos sistemáticamente organizados, más que probar una hipótesis se buscó seleccionar información que haga posible entender la dinámica empresarial en el contexto institucional peruano. Para ello se procedió a la búsqueda y revisión de la bibliografía existente y a la realización de entrevistas en profundidad con académicos, dirigentes empresariales $y$ personas que ocupaban o habían ocupado puestos de responsabilidad en el Estado, incluidos dos ex presidentes de la República (ver anexo). El principio fundamental observado en este proceso fue la mayor imparcialidad en la compilación y registro del pensamiento de los autores citados y de las personas entrevistadas. Se ha practicado una suerte de eclecticismo para tratar de explicar el efecto que ha causado el marco institucional en la evolución y desarrollo de las organizaciones empresariales en el Perú. 


\section{PNB per cápita de algunos países}

Año 2000

\begin{tabular}{|l|r|r|}
\hline \multicolumn{1}{|c|}{ Países } & PNB (US\$ millones) & PNB per cápita (US\$) \\
\hline Alemania & 2100000 & 25050 \\
Argentina & 275500 & 7440 \\
Brasil & 606800 & 3570 \\
Canadá & 647100 & 21050 \\
Chile & 69900 & 4600 \\
Estados Unidos & 9600000 & 34260 \\
Francia & 1400000 & 23670 \\
Italia & 1200000 & 20010 \\
Japón & 4300000 & 34210 \\
Perú & 53900 & 2100 \\
Reino Unido & 1500000 & 24500 \\
Suiza & 273700 & 38120 \\
Uruguay & 20300 & 6090 \\
Venezuela & 104100 & 4310 \\
\hline
\end{tabular}

Fuente: World Bank Group (2001).

\section{Instituciones y desarrollo de las organizaciones empresariales en el Perú}

Las economías actuales son economías organizacionales en las cuales las empresas son las protagonistas de la creación de valor y del progreso económico de los países (Ghoshal, Bartlett y Moran, 1999), y lo que hacen las economías nacionales es reflejar el éxito y el fracaso de aquéllas. El papel de las empresas en la sociedad es sumamente importante, ya que ellas son las encargadas de generar riqueza y bienestar. Kisic (1999: 13) afirma de manera simplificada que sin desarrollo empresarial no habrá una recaudación fiscal sustantiva que permita «... desarrollar el potencial del país, ni las capacidades individuales de sus ciudadanos; y sin el desarrollo de nuestros ciudadanos no tendremos una sociedad estable».
Es útil tomar los indicadores económicos de un país como una medida del desarrollo de sus empresas. Las cifras mostradas en el cuadro adjunto no sólo confirman lo que intuitivamente se descubre por observación, también permiten inferir el bajo grado de desarrollo de las organizaciones empresariales peruanas.

A continuación se desarrolla el análisis de cada una de las variables incluidas en el modelo de investigación presentado, para intentar una explicación del porqué de este panorama desalentador.

\subsection{Cultura}

La ética en el comportamiento social, el estilo de liderazgo, la religiosidad, la manera como se realizan las transacciones y la diversidad étnica son los principales aspectos que delimitan las características culturales de una sociedad. 


\section{Ética en el comportamiento social}

Hay una percepción extendida acerca de que la sociedad peruana sufre un estado de anomia, una crisis de valores, porque «se aplaude al vivo que se hace popular o rico empleando procedimientos dudosos [...]. Pareciera que ante esta situación, las clases dirigentes mostraran apatía en la medida en que no se sientan afectadas» (Moreyra, 1996: 41-42). La sociedad peruana «exalta el mínimo esfuerzo frente al espíritu de superación [...], condena el éxito [...]; nuestra mediocridad y mezquindad nos hacen desvirtuar y minimizar los triunfos de los demás tal vez porque así obligamos a todos a mantener una conducta pusilánime y timorata» (Iwasaki, 1988: 134-135). Corrupción, nepotismo, tráfico de influencias, violación de la propiedad privada, abuso de autoridad, deslealtad, impunidad, cinismo, deshonestidad, desorden, impuntualidad, entre otras, son sólo algunas manifestaciones del estado de anomia de la sociedad peruana.

Algunos autores opinan que este problema se origina en la educación y se remonta a los valores inculcados en la niñez, pues «el niño aprende que para ganarse el respeto y la amistad de los demás debe ser malicioso, abusivo o desconfiado» (Iwasaki, 1988: 133).

Vargas Llosa (citado por De Soto, 1987: XXIII) ensaya una posible explicación a la situación anómica que atraviesa el Perú y descalifica al mercantilismo por «corruptor e ineficiente», ya que el éxito en este sistema «depende de la aptitud para granjearse las simpatías de los funcionarios públicos (lo que a menudo, significa simplemente la aptitud para corromperlos)».
Para superar el estado de anomia actual se debería rechazar cualquier forma de discriminación o dogmatismo e inculcar el valor ético de la solidaridad, ya que tal como lo resumió Kant (citado por Moreyra, 1996): «Para yo gozar de mi libertad debe haber un mínimo de justicia».

La principal dificultad reside en la mucha frecuencia con que los principios éticos se oponen a los intereses particulares, de lo cual se desprende que el problema central es la definición de una escala de valores. Y la empresa no es ajena a estas reflexiones de orden ético. Es necesario reconocer que el funcionamiento de una empresa implica «un nuevo contrato moral con los empleados y con la sociedad, reemplazando la explotación paternalista y la apropiación del valor a favor del empleo y la creación de valor estableciendo una relación de destino compartido» (Ghoshal, Bartlett y Moran, 1999: 13). Por tanto, a la empresa le corresponde asumir un papel que promueva la honestidad, la confianza y el respeto a los valores morales de la sociedad.

Todos los entrevistados señalaron que en el Perú no existe el convencimiento de cumplir con las obligaciones impuestas por la vida en sociedad; por el contrario, muchas veces solamente el temor a la sanción obliga al cumplimiento de las normas. Algunos atribuyeron esta conducta a la impunidad que reina en el país, casi siempre amparada en el poder, pero todos coincidieron en señalar la distorsión de los valores en la educación como la principal causa. La minoría de los entrevistados se animó a describir una actitud rentista en los empresarios peruanos; otros remarcaron la creatividad, la iniciativa, la tenacidad y el honesto espíritu de lucha del trabajador peruano, característi- 
cas que debieran, en su opinión, ser correctamente encaminadas para que se traduzcan en resultados concretos que contribuyan al desarrollo del país.

\section{Estilo de liderazgo}

Se considera que el Perú se caracteriza por una tradición autoritaria originada en el Tahuantinsuyo y mantenida invariable durante el periodo colonial, pues, al momento de la conquista España implantó conceptos feudales que apreciaban el autoritarismo. Cuando el Perú nació a la vida republicana, la sociedad sufrió transformaciones muy débiles y no se modificó la cultura autoritaria. Se mantuvo la misma relación vertical por la cual los nobles, luego criollos y después blancos dominaron a las mayorías sustentando su poder en diferencias socioculturales y raciales. Se sabe que la nobleza española que vino a asentarse en América durante la Colonia despreciaba el trabajo y el comercio; por tanto, eran tareas «indignas» que otros debían realizar bajo un régimen de sometimiento. Así, a lo largo de la historia peruana el estilo autoritario de conducir diferentes organizaciones se ha moldeado a partir de la proclamación de privilegios -surgidos por aspectos hereditarios-, antes que por méritos obtenidos (Arias, 1994).

En las empresas peruanas no es común confiar en los subordinados (Whyte y Flores, 1963).

El autoritarismo eleva tremendamente los costos de transacción, a la vez que genera ineficiencias en los procesos de las empresas, mientras que la confianza los elimina, pues «solo es posible economizar sustancialmente en costos de transacción si [las organizaciones] son suple- mentadas por capital social y confianza» (Fukuyama, 1995: 11).

Los entrevistados reconocieron que, si bien aún subsisten en las empresas peruanas fuertes rasgos de autoritarismo, principalmente en aquellas de propiedad familiar, se observa una tendencia al cambio y una corriente a favor de promover la confianza al interior de las organizaciones. Coincidieron en señalar la necesidad de adoptar un nuevo esquema de funcionamiento que sea más participativo y esté sustentado en la responsabilidad individual.

\section{Religiosidad}

La forma como se realizó la evangelización en el Perú, la influencia que ha ejercido el clero en la sociedad peruana y los valores morales que promueve el Cristianismo determinan la conducta de los individuos en los diferentes campos de la actividad humana; entre ellos, el quehacer empresarial.

La experiencia de los países occidentales revela el vínculo entre capitalismo y protestantismo. Mariátegui (1928; 1965: 154) afirmaba que «el protestantismo y el liberalismo correspondieron, como corriente religiosa y tendencia política respectivamente, al desarrollo de los factores de la economía capitalista». Belaunde (193; 1980: 88) reconocía que en las sociedades protestantes predominó un sentido económico y político, pero condenaba el hecho de que el desarrollo industrial significó «la abrogación de las condenaciones del Catolicismo, contra el interés y contra la usura».

En la universidad norteamericana se promovía la santidad de la propiedad, 
fomentando el individualismo como motor del desarrollo (Mariátegui, 1928; 1965). Contrariamente, en los países sudamericanos se promueve un mal llamado espíritu solidario, cayendo en la «[...] falsa ética de la justicia distributiva... [donde] no hay derechos de propiedad firmes [y] no existen incentivos legales para crear prosperidad...» (De Soto, 1987: 250). Al respecto uno de los entrevistados explicó la incorrecta interpretación de la Biblia que subyace en el hecho de estigmatizar la riqueza y alabar la pobreza, pues se descalifica la riqueza de los demás, pero se desea ser rico. Según el mismo entrevistado, subsisten aún algunos rasgos de fanatismo en el tema religioso que podrían inducir a error si no se analizan las expresiones con objetividad.

Históricamente, la iglesia Católica ha jugado un papel fundamental en la formación de la moral de la sociedad peruana y ha desarrollado una importante tarea educativa. Pese a que durante mucho tiempo estuvo fuertemente vinculada al poder político y económico, en las últimas décadas ha experimentado una transformación sustancial en cuanto a su función social, actitud que se manifiesta en su significativa labor de apoyo a la comunidad, tanto con ayuda humanitaria como mediante la organización de comunidades productivas.

\section{La manera como se realizan las transacciones}

Según algunos estimados, entre el $40 \%$ y el $50 \%$ de la población peruana económicamente activa trabaja en el sector informal. La informalidad es «aquella parte de la economía conformada por empresas no registradas oficialmente, que no están sometidas a la legislación laboral y tribu- taria y que no están controladas por el estado en sus procesos productivos o comerciales» (Arellano, 1990: 9). La informalidad surge como consecuencia de la falta de capacidad del Estado para generar las condiciones que permitan al sector formal desarrollar inversión y puestos de trabajo (De Soto, 1987).

Algunos entrevistados señalaron que la informalidad surge debido a las fallas de la institucionalidad formal en el país, marco en el cual muchos peruanos, en su mayoría quienes emigraron del campo a las ciudades, no encontraron garantías ni seguridad para su desarrollo y decidieron formar su propia institucionalidad informal. Otros entrevistados expresaron que la informalidad representa un cierto dinamismo nacido de la iniciativa y el espíritu de superación y progreso de los individuos ante la escasez de oferta laboral formal, en medio de una situación de crisis.

La informalidad no contribuye al desarrollo empresarial, pues el progreso del país no se puede sustentar en una gran cantidad de microempresas informales que operan en condiciones de supervivencia, sin capacidad para generar excedentes ni utilidades que luego se conviertan en ahorro, inversión o capital.

Los autores coinciden en señalar que un factor muy importante para contrarrestar el grado de informalidad en el país es la mejora del sistema educativo.

\section{Diversidad étnica}

En la composición étnica del Perú predomina el componente autóctono, característico del $45 \%$ de la población (Famighetti, 1997). La población aborigen «simboliza la personalidad histórica de la 
nacionalidad» (Belaúnde, 1930;1980: 15); sin embargo, estuvo impedida de convertirse en protagonista del desarrollo y resultó siendo un lastre para el país por el estado de marginación y abuso a la que fue sometida.

Más allá de los resultados de la reforma agraria implantada en 1968, es indudable que, si bien no marcó un punto de quiebre en la conformación de la sociedad peruana, por lo menos aceleró el proceso de «cholificación» que transcurre actualmente y se expresa en el deseo de los peruanos andinos de ser partícipes del desarrollo nacional y beneficiarios del progreso. No obstante, la sociedad peruana mantiene fuertes prejuicios raciales porque «la marca colonial es aún tan fuerte que [...] 'blancos' todavía 'cholean' a quienes no lo son» (De Althaus, 2000) y «le reconocen al cholito venido de la puna un derecho a vivir entre nosotros sólo a condición de que nos necesite para organizarlo o emplearlo, en una ubicación claramente dependiente...» (De Soto, 1987: 296).

El Perú experimenta un proceso de transición; de ser una sociedad dual pasa a ser una sociedad más integrada (Moreyra, 1996). El problema de la dualidad ya fue explicado por Mariátegui (1928; 1965: 178), quien afirmó la necesidad de «resolver una dualidad de raza, de lengua y de sentimiento, nacida de la invasión y conquista del Perú autóctono por una raza extranjera que no ha conseguido fusionarse con la raza indígena ni eliminarla ni absorberla».

Refiriéndose a lo mismo, Mariátegui (1928; 1965) señaló que el problema no era solamente de carácter humanitario, era también de orden económico, porque el progreso del Perú sería ficticio, o por lo menos no sería peruano, mientras no significara el bienestar de todos los peruanos. Resulta curioso que el proceso de industrialización en el Perú recién se inicie con la llegada de reducidas y espontáneas migraciones europeas hacia fines del siglo XIX (Durand, 1988).

El problema no radica en la diversidad étnica peruana, sino en el hecho de que los aborígenes fueron históricamente excluidos. La evidencia empírica demuestra que las clases sociales menos favorecidas, en las cuales de manera coincidente se incluyen los ciudadanos de origen autóctono, son las más ávidas por acceder a la educación como un medio para lograr el ascenso social y económico. He ahí uno de los principales puntos de apoyo para lograr la integración y el bienestar general. El gran reto del Perú está en incorporar a la economía a toda la población.

El análisis presentado sobre los factores culturales identificados conduce a pensar que, en general, éstos no han favorecido el desarrollo de las organizaciones empresariales en el Perú.

\subsection{Educación}

¿Cuál es la relación entre las instituciones y la educación? Las instituciones no nacen con el individuo, son propias de una cultura. Al nacer la persona en una cultura determinada, en un momento histórico determinado, pasa por un proceso de «aculturación», por el cual se le van enseñando las instituciones que rigen en esa cultura donde se encuentra. El aprendizaje de las instituciones se logra por medio de las organizaciones de educación formal y también a través de la sociedad de manera difusa, pues al convivir 
con sus semejantes el sujeto es impulsado a seguir las normas institucionales. $\mathrm{La}$ educación no es un hecho que se presente en la sociedad de manera aislada, de modo que quien acude a centros de educación formal recibe educación y aquel que no lo hace no la recibe; un individuo no se nutre de educación solamente en dichos centros.

En el campo de la educación formal, los profesores se encargan de transmitir los valores y reglas sociales, con los cuales se educa a los alumnos conforme a instituciones que favorezcan el desarrollo. La educación formal es un medio poderoso para el cambio.

La sociedad cumple su papel educador al transmitir costumbres sociales. Así, considerando que el poder del Estado es el más grande dentro de una sociedad, los funcionarios públicos tienen mayor poder que los ciudadanos particulares, razón por la cual su comportamiento moral o amoral tendrá un efecto multiplicador en la sociedad. Por lo tanto, desde un punto de vista educativo, si hay un comportamiento moral generalizado en el Estado, ello repercutirá positivamente en la sociedad.

Adicionalmente, los medios de comunicación masiva constituyen un agente clave en el proceso de moldear instituciones en una sociedad, ya que influyen en el pensamiento y comportamiento del individuo mediante la difusión de determinada información. Estudios sobre valores de familia, educación, religión y política «han encontrado que cuanto más televisión ven los niños, mayor probabilidad hay de que adopten las visiones que los medios de comunicación difunden, [desterrando] el comportamiento que obser- van en su propia familia, educación y religión» (Beniger, 1990: 224).

El proceso de aprendizaje de las normas requiere de la interiorización de las mismas por parte de la población. Ésta no sólo debe percibir que las normas se cumplen y confiar en que así será siempre, también necesita entenderlas y creer que su cumplimiento es beneficioso para la sociedad a la cual pertenece. La sola aplicación rigurosa de normas legales, sin el apoyo del proceso de aprendizaje, puede originar que la población cumpla las normas únicamente por temor a las sanciones. En este caso, las normas no constituyen instituciones, pues para que así sea es necesario que el individuo crea profundamente en lo ventajoso de comportarse de acuerdo con ellas. Esto se logra mediante la creación tanto de normas que contengan instituciones preexistentes como de organismos encargados de hacerlas cumplir.

\subsection{Estado}

Para que una sociedad pueda desenvolverse en un ambiente de bienestar y seguridad y pueda desarrollarse de la manera más eficiente, es deber de sus representantes establecer las normas que rijan y limiten el comportamiento de los individuos y las organizaciones que la componen.

Estudios del Banco Mundial señalan que las sociedades más desarrolladas «son aquellas que lograron establecer relaciones de cooperación entre el estado, el libre juego de las fuerzas del mercado y la participación activa de la sociedad civil» (Guerra-García, 1999: 23). El consenso busca fijar reglas de juego estables a través del tiempo, que no se vean in- 
fluenciadas por la coyuntura política. Las reglas de juego estables deben nacer de la sociedad organizada, de la conjunción de esfuerzos entre los organismos del Estado y los gremios empresariales y civiles del país, y no de la imposición de algún sector de la sociedad. El Estado es responsable de establecer el ordenamiento legal e institucional necesario para permitir que las unidades productivas sean capaces de generar excedentes que luego se canalicen hacia el ahorro interno, el capital y la inversión (De Soto, 1987).

En los últimos años se ha generado gran controversia sobre la función del Estado en la economía del país. Hay dos posiciones antagónicas. Una de ellas promueve la reducción del Estado a su mínima expresión, para dejar la creación de riqueza al libre accionar de las fuerzas del mercado. Por el contrario, la otra posición sostiene la necesidad de una fuerte presencia del Estado para garantizar el adecuado funcionamiento de la economía. Atrás quedaron las tesis que concebían al Estado como un agente económico que intervenía en la economía a través de empresas estatales o regulaba los precios en el mercado. Hoy se acepta que el Estado intervenga a través de un marco normativo para corregir las imperfecciones de los mercados y evitar que éstas generen pérdida de eficiencia social. En este nuevo contexto, es cada vez menor el espacio para prácticas rentistas.

Desde una perspectiva histórica, se podría afirmar que las políticas adoptadas por los diferentes gobiernos han sido inestables y oscilantes de acuerdo con el grupo de poder al cual se pretendía favorecer, lo cual ha ocasionado que el marco legal y normativo sea inestable, impida el planeamiento de largo plazo y genere una visión de corto plazo en los empresarios.

\subsection{Globalización}

En el fenómeno de la globalización, los medios de comunicación masiva participan de un modo crucial al difundir creencias y valores foráneos a una gran masa de personas. Este hecho, por un lado, contribuye a integrar la sociedad local al resto del mundo y enriquece la cultura nacional mediante la asimilación de aspectos culturales desconocidos. Sin embargo, por otro lado, podría afectar la formación de la nacionalidad al transmitir costumbres de otras culturas.

El proceso de globalización ha determinado un nuevo marco institucional para las organizaciones empresariales peruanas, ha redefinido la forma de hacer negocios y ha modificado las relaciones entre los distintos agentes del mercado en un ambiente de altísima competencia y gran dinamismo organizacional y tecnológico. Se ha formado una economía en la que van desapareciendo las fronteras comerciales entre los países y las barreras naturales al comercio internacional; cada vez el mundo es más pequeño en términos de distancias y es cada vez más grande en términos de tamaño del mercado.

Durante muchas décadas, las empresas peruanas vivieron de las oportunidades concedidas por un mercado interno cautivo y poco exigente que no las obligó a ser dinámicas y competitivas. Hoy en día, la tendencia mundial señala un mercado libre altamente competitivo; por tanto, el desarrollo e incluso la supervivencia de las empresas peruanas dependerán de su capacidad de adaptación a 
este nuevo mundo global con alta competitividad.

\subsection{Reflexión}

La evidencia recogida y analizada permite concluir que el marco institucional en el Perú, en general, no ha favorecido el desarrollo de las organizaciones empresariales. En efecto, ciertas actitudes y costumbres arraigadas son trasladadas a las relaciones sociales y a las empresas y, en consecuencia, afectan el rendimiento y restringen la posibilidad de desarrollo de éstas. No se pretende desconocer las virtudes de muchos empresarios de la sociedad peruana, quienes, basados en su creatividad, perseverancia, esfuerzo y tenacidad, han logrado superar los obstáculos que debieron enfrentar, pero aún falta mucho por hacer.

Además, no se cuenta con una visión de país que oriente el rumbo de la economía en el largo plazo y guíe los esfuerzos de todos los agentes económicos en la misma dirección. Es indispensable llegar al consenso nacional, lo cual demanda, en primer lugar, la presencia de partidos políticos, colegios profesionales, gremios empresariales y laborales, entre otros, en los que la sociedad sea efectivamente representada. Se requiere también una democracia sólida, sustentada en un adecuado equilibrio de poderes, una legislación que contemple los intereses nacionales, seguridad jurídica y organismos cuyo accionar sea transparente. Es indispensable, entonces, mejorar el sistema educativo y el nivel cultural de la sociedad para generar el cambio institucional que favorezca el desarrollo de las organizaciones empresariales $\mathrm{y}$, por tanto, del país.

\section{Lineamientos de cambio: una nueva cultura de responsabilidad social}

Es evidente que generar el cambio institucional requiere de un proceso que abarque más de una generación de peruanos, pues cualquier estrategia que propugne el cambio debe sustentarse en la educación, considerada la única herramienta de cambio sostenible. La educación como medio de transferencia de conocimientos, valores y principios se inicia en el hogar, donde se aprende, a través del ejemplo, las normas de convivencia; de allí la importancia gravitante de la familia como constructora del cambio institucional. Además, no se puede desconocer la gran importancia de los colegios y universidades para la educación, no sólo porque otorgan instrucción adecuada, también debido a la formación en valores que proporcionan. Para lograr cambios en las instituciones educativas se requiere, en primer lugar, maestros preparados, adecuadamente remunerados, muy motivados y conscientes del papel que les compete en el desarrollo del país; además, por supuesto, de la infraestructura y los medios tecnológicos que demanda una educación competitiva en la economía global.

El aprendizaje de las instituciones y su fortaleza se inicia, como se ha visto, en el control social, gran parte del cual reside en los poderes coercitivos del Estado para hacer cumplir las normas. Por tanto, el Estado debe promover prácticas honestas en la interacción entre los individuos y fijar normas de conducta, a través del buen ejemplo de los funcionarios públicos. Si el Estado hace un uso racional y ético de sus poderes para afianzar las instituciones, sin discriminación ni favoritismos, éstas terminarán siendo asimiladas. 


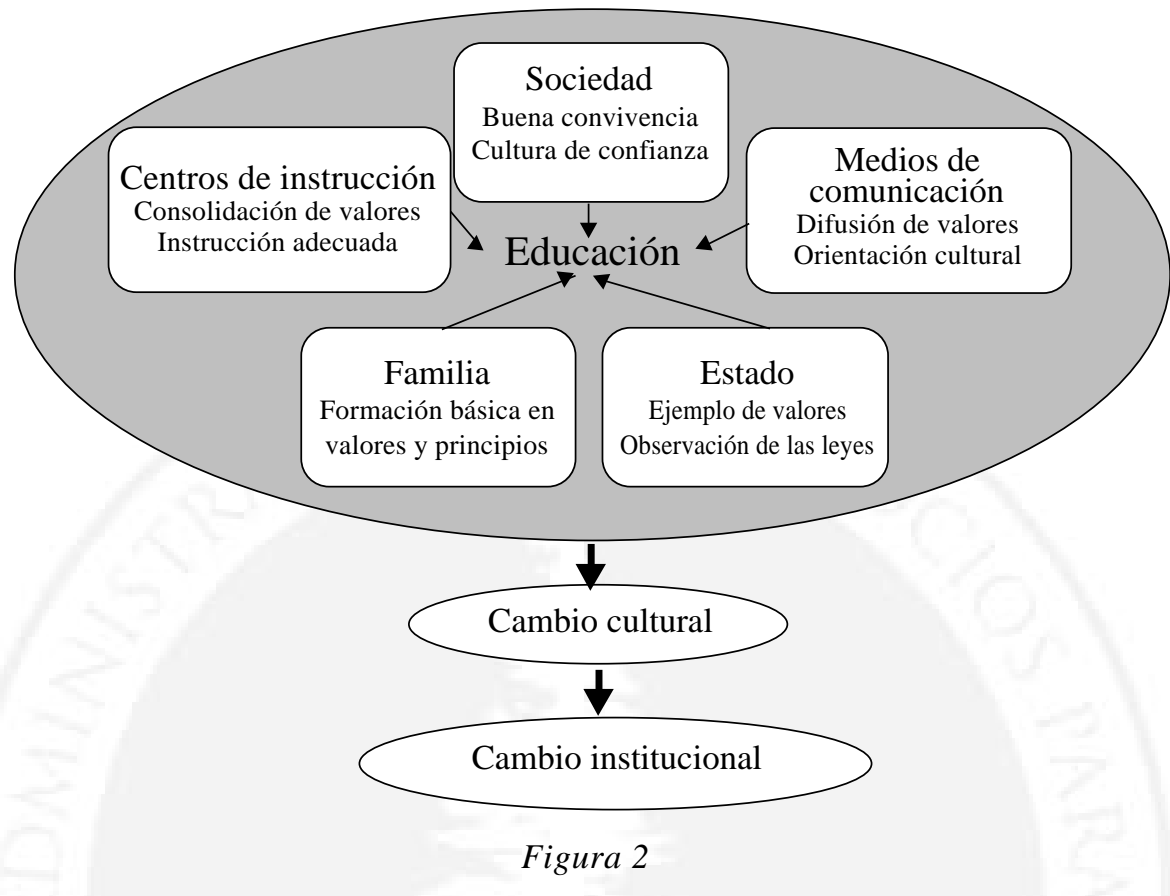

Adicionalmente, no se puede desconocer la importancia de los medios de comunicación masiva en el proceso educativo de la población. En efecto, la radio, los diarios, las revistas y, principalmente, la televisión tienen tanto la responsabilidad como la obligación moral de difundir cultura e inculcar en la población -sobre todo a los niños- un conjunto de instituciones basadas en principios y valores que favorezcan el desarrollo del país. La importancia de los medios masivos de comunicación radica en su fuerza para reducir o modificar la influencia que la familia y los colegios pueden ejercer sobre la formación cultural de los niños.

Se postula, entonces, que cualquier proceso que pretenda eliminar actitudes cuya influencia haya sido negativa para el desarrollo de las organizaciones empresariales en el Perú debe sustentarse en la educación y en la promoción de ésta por los diferentes actores de la sociedad, tal como se esquematiza en la figura 2.

Es innegable que el progreso y el bienestar de una sociedad están determinados, en gran medida, por su capacidad para producir bienes, y no hay duda de que las responsables de crear riqueza en una economía de libre mercado son las organizaciones empresariales. En ellas la sociedad deposita su confianza para la generación de valor; si no lo hacen, el país quedará condenado a vivir en condiciones de suma precariedad.

Las empresas se ven influidas por variables que afectan su funcionamiento y definen su desarrollo, pero también contribuyen a moldear instituciones a través de cambios al interior de su organización $\mathrm{y}$ de medidas que puedan influir sobre su entorno institucional. Por un lado, las empresas deben orientarse a la creación 
de valor, mediante la generación de nueva riqueza para ellas y la sociedad. Para los empresarios peruanos, crear valor debe significar eliminar por completo los vestigios de una mentalidad rentista y buscar la competencia en libertad, valorar el mérito y asumir el riesgo empresarial. Las empresas deben potenciar la capacidad y creatividad de sus empleados y convertirlos en socios de su éxito.

Por otro lado, la empresa privada, además de su interés netamente lucrativo, debe asumir la responsabilidad social que le compete. El que la empresa cumpla con su responsabilidad social no sólo otorga beneficios a la sociedad, también conlleva provecho para la empresa misma. Se beneficia del aumento de la productividad de sus empleados, de la mayor identificación de sus trabajadores con ella, y de su reputación e imagen frente a sus clientes, competidores y proveedores. En general, los beneficios para la empresa deben reflejarse no sólo en un mayor nivel de utilidades, también en una mejor posición competitiva para la generación de riqueza.

Por su parte, el Estado debe tender puentes de comunicación con la sociedad, y la sociedad está representada por los gremios empresariales y profesionales, las organizaciones civiles y los partidos políticos. Por tanto, estos organismos deben ser los llamados a lograr consensos en la búsqueda de reglas de juego estables a lo largo del tiempo. Es imposible buscar el desarrollo de las organizaciones empresariales peruanas si la sociedad en su conjunto no se pone de acuerdo acerca de adónde quiere llegar y cómo pretende hacerlo. Resulta imprescindible lograr una visión de país que permanezca y trascienda el tiempo.

\section{Conclusiones}

Como respuesta a la pregunta de investigación formulada al inicio de este trabajo, se ha llegado a la conclusión de que las instituciones en el Perú, en general, no han favorecido el desarrollo de las organizaciones empresariales, porque se reconoce la existencia de hábitos y convenciones interiorizados en la sociedad que, por el contrario, han entorpecido el desarrollo de las empresas. El cambio de ciertos patrones culturales requiere de un proceso de educación sustentado en la familia, consolidado en los centros de instrucción, reforzado a través de los medios de comunicación masiva, promovido por el Estado y adoptado por las personas en la forma de un compromiso social, el mismo que abarcará más de una generación de peruanos.

El hecho de que nunca se contara con una visión de país resultado del consenso de la mayoría de peruanos provocó que los diferentes gobiernos siguieran políticas cambiantes y a veces contradictorias cuyo propósito, en general, era favorecer a ciertos grupos. En ese contexto, muchos empresarios adoptaron actitudes cortoplacistas y rentistas y trataron de obtener favores del gobierno. Corregir esta situación demanda el compromiso de los peruanos organizados alrededor de una visión común que incorpore los intereses del país. De lo contrario, los empresarios se limitarán a planificar y actuar dentro de un horizonte de corto plazo y los inversionistas buscarán obtener utilidades y retirarlas del proceso empresarial lo más pronto posible, en un ambiente confuso, propicio para el ejercicio de prácticas poco transparentes. 


\section{Futuras investigaciones}

La presente investigación, de carácter exploratorio, ha identificado algunos aspectos con relación a la institucionalidad que permiten iniciar una discusión seria sobre el tema. Al mismo tiempo, abre una serie de interrogantes y nuevas posibilidades de investigación, razón por la cual se sugiere que el esfuerzo hecho aquí sea continuado a través de estudios complementarios, tales como:
- Análisis comparativo entre el Perú y otros países cuyo desarrollo empresarial sea significativamente mayor, acerca de los principales aspectos institucionales identificados en el presente trabajo.

- Definición del perfil del empresario peruano, distinguiendo entre empresarios formales e informales, y entre propietarios según el tamaño de sus empresas: micro, pequeñas, medianas o grandes.

\section{Referencias bibliográficas}

ARELLANO Cueva, R. (1990). Estrategias del comercio informal: Explicación del crecimiento explosivo del sector en América Latina. Academia. $\mathrm{N} .{ }^{\circ}$ 5, págs. 9-23.

ARIAS QUINCOT, C. (1994). La modernización autoritaria. Lima: Fundación Friedrich Ebert.

BELAÚNDE, V. A. (1980). Realidad nacional. 4ta ed. Lima: Interbanc. Edición original en 1930.

BENIGER, J. y HERBST, S. (1990). Change in Societal Institutions. Mass Media and Public Opinion: Emergence of an Institution. New York: Plenum.

BENTON, W. (ed.). (1964). Enciclopedia Barsa de consulta fácil. Chicago: Encyclopedia Britannica. Vols. 1-15.

BLOOR, D. (1997). Wittgenstein, Rules and Institutions. Gales: Routledge.

CONGRESO DE LA REPÚBLICA DEL PERÚ. (1993). Constitución Política del Perú 1993. http://www.congreso.gob.pe/ index.htm.

DE ALTHAUS, J. (2000). ¿Inca o profesional? El Comercio. Lima, 31 de mar., A4.
DE SOTO, H. (1987). El otro sendero. Lima: Instituto Libertad y Democracia.

DOUGLAS, M. (1996). Cómo piensan las instituciones. Madrid: Alianza Editorial.

DURAND, F. (1988). La burguesía peruana: los primeros industriales, Alan García y los empresarios. Lima: Centro de Es tudios y Promoción del Desarrollo, DESCO.

FAMIGHETTI, R. (ed.). (1997). The World Almanac and Book of Facts 1998. New Jersey: World Almanac Books.

FAURE, G. O. y RUBIN, J. Z. (1993). Culture and Negotiation. Newbury Park: Flage Publications.

FUKUYAMA, F. (1995). Trust: The Social Virtues and the Creation of Prosperity. New York: The Free Press.

GARCÍA HOZ, V. (ed.). (1964). Diccionario de pedagogía. Barcelona: Labor. Vols. 1-2.

GHOSHAL, S.; BARTLETT, C. A. y MORAN, P. (1999). Un nuevo manifiesto a favor del 'management'. Harvard Deusto Business Review. N. ${ }^{\circ}$ 93, págs. 12-26. 
GUERRA-GARCÍA PICASSO, G. (1999). Reforma del Estado en el Perú: pautas para reestructurar el poder ejecutivo. Lima: Agenda Perú.

IWASAKI Cauti, F. (1988). Nación peruana: entelequia o utopía; trayectoria de una falacia. Lima: Centro Regional de Estudios Socio Económicos.

KISIC WAGNER, D. (1999). Empresa y el desarrollo nacional. Gerencia. Lima, ago. 240, págs. 12-15.

MARIÁTEGUI, J. C. (1965). Siete ensayos de interpretación de la realidad peruana. $10^{\mathrm{a}}$ ed. Lima: Amauta. Edición original de 1928.

MOREYRA LOREDO, M. (1996). La ética como base de una visión. En: Conferencia Anual de Ejecutivos XXXIV. Perú siglo 21: Propuestas para una visión compartida. Arequipa. Vol. 4, págs. 41-50.
NORTH, D. (1993).Instituciones, cambio ins titucional y desempeño económico. México: Fondo de Cultura Económica.

PRITZL, R. F. J. (1996). Instituciones, incertidumbre y desarrollo: la nueva economía institucional y su aplicación a problemas económicos. Contribuciones. N. ${ }^{\circ}$, págs. 221-250.

SELZNICK, P. (1948). Foundations of the Theory of Organization. American Sociological Review.

WHYTE, W. F. y FLORES, G. (1963). Los valores y el desarrollo económico en el Perú. Lima: SENATI.

WILLIAMSON, O. E. (1989). Las instituciones económicas del capitalismo. México: Fondo de Cultura Económica.

WORLD BANK GROUP. (2001). Country Data. http://www.worldbank.org. (jul.). 


\section{ANEXO \\ Relación de personas entrevistadas para esta investigación}

1. Enrique Arroyo Rizo-Patrón

Gerente general de la Asociación de Bancos del Perú (Asbanc)

2. Manuel Barnechea Diez-Canseco Gerente de Administración y Finanzas de la Bolsa de Valores de Lima (BVL)

3. Fernando Belaúnde Terry Ex presidente constitucional de la República del Perú

4. Roque Benavides Ganoza Ex presidente de la Confederación Nacional de Instituciones Empresariales del Perú (Confiep)

5. Jorge Chian Chong

Gerente general de la Cámara de Comercio de Lima (CCL)

6. Lourdes Flores Nano Ex congresista y ex candidata a la Presidencia de la República

7. Margarita Giesecke Sara-Lafosse Historiadora e investigadora académica

8. Daniel Linares Bazán Director ejecutivo de la Asociación de Radio y Televisión (ARYTV)

9. Eduardo McBride Quiroz Ex presidente de la Asociación de Exportadores (ADEX)

10. Francisco Morales Bermúdez Cerrutti Ex presidente de la República del Perú
11. Álvaro Quijandría Salmón Ex presidente de la Sociedad de Empresarios Agrarios del Perú y actual ministro de Agricultura

12. Guillermo Rey Terry

Magistrado del Tribunal Constitucional del Perú

13. Julio Rizo Patrón Belgrano Gerente general de la Sociedad Nacional de Industrias (SNI)

14. Santiago Roca Tavella Economista, profesor principal y director de Investigaciones de ESAN

15. Ricardo Rodríguez Gerente general de la Cámara Peruana de la Construcción (Capeco)

16. Francisco Sagasti Hochhansler Investigador y director de Agenda Perú

17. Percy Separovich Gerente de la Asociación Peruana de Avicultura (APA)

18. Carlos Torres y Torres Lara Ex congresista

19. Juan Julio Wicht Sacerdote jesuita y decano de la Facultad de Economía de la Universidad del Pacífico

20. Jorge Zúñiga Quiroz

Gerente general de la Cámara Nacional de Turismo (Canatur) 